\title{
Asymptomatic pulmonary embolus masquerading as acute anteroseptal myocardial infarction
}

\author{
Jeanne Noble, MD, MA*; Amandeep Singh, $\mathrm{MD}^{\dagger}$
}

\section{ABSTRACT}

Pulmonary embolism (PE) is an uncommon and often overlooked cause of ST-segment elevation on the electrocardiogram (ECG). Emergent echocardiography has been cited as a means to rapidly distinguish acute myocardial infarction from PE. However, both of these conditions can present with focal wall motion abnormalities. We report a case of a 51-year-old asymptomatic male who presented to our emergency department with anterior ST-segment elevation and right-heart strain on an ECG. The clinical diagnosis of ST elevation myocardial infarction was in doubt, and an echocardiogram was obtained while the patient was in the emergency department. Although a focal area of hypokinesia was observed on echocardiography, cardiac catherization did not demonstrate any evidence of acute coronary occlusion. A computed tomographic angiogram of the chest was subsequently obtained, which demonstrated evidence of submassive pulmonary emboli. Our case highlights the limited utility of emergent echocardiography in cases of ST-segment elevation.

\section{RÉSUMÉ}

L'embolie pulmonaire (EP) est une cause rare de susdécalage du segment ST qui passe souvent inaperçue à I'électrocardiogramme (ECG). L'échocardiographie émergente a été citée comme un moyen de distinguer rapidement I'infarctus aigu du myocarde de I'EP. Toutefois, ces deux conditions peuvent présenter des anomalies de la cinétique de la paroi libre. Nous présentons le cas d'un homme de 51 ans asymptomatique s'étant présenté à notre service d'urgence avec un sus-décalage du segment ST en antérieur et une surcharge ventriculaire droite sur l'ECG. Le diagnostic clinique d'infarctus du myocarde avec sus-décalage du segment ST était peu probable, et un échocardiogramme a été obtenu pendant que le patient était à l'urgence. Même si l'échocardiographie a révélé une hypokinésie locale, le cathétérisme cardiaque n'a donné aucune preuve d'occlusion coronaire aiguë. Une angiographie par tomodensitométrie du thorax réalisée par la suite a mis en évidence une embolie pulmonaire submassive. Notre cas illustre l'utilité limitée de l'échocardiographie émergente pour les cas de susdécalage du segment $\mathrm{T}$.

Keywords: embolus, infarction, myocardial, pulmonary

\section{CASE REPORT}

A 51-year-old man with a history of multiple sclerosis was sent to our hospital from a nursing facility for an abnormal electrocardiogram (ECG) that demonstrated ST-segment elevation in the precordial leads V1 to V3. Earlier in the day, the patient was noted to have had a low-grade temperature, a single episode of vomiting, and transient hypotension, prompting the ordering of the ECG by his primary medical provider. On presentation to the emergency department (ED), the patient had no complaints and specifically denied chest pain, shortness of breath, or cough.

The patient's vital signs were as follows: blood pressure 138/109 $\mathrm{mm} \mathrm{Hg}$, heart rate 140 beats/min, respiratory rate 32 breaths $/ \mathrm{min}$, temperature $36.9^{\circ} \mathrm{C}$, and pulse oximetry of $100 \%$ on room air. Examination of the heart and lungs was normal, as was his abdominal examination. His extremities were thin and showed no sign of swelling, erythema, or tenderness. His mental status was described as alert and cooperative, with repeated denial of discomfort. It was later learned that the patient carried the diagnosis of euphoria sclerotica (multiple sclerosis-related euphoria). ${ }^{1}$

A complete blood count, serum chemistries, renal function, and glucose were all normal. Cardiac specific

From the *Department of Emergency Medicine, University of California, San Francisco, CA; and tDepartment of Emergency Medicine, Alameda Country Medical Center, Highland Hospital, Oakland, CA.

Correspondence to: Dr. Jeanne Noble, Department of Emergency Medicine, University of California, San Francisco, 505 Parnassus Avenue, Room L138, San Francisco, CA 94143-0208; Jeanne_noble@yahoo.com.

This article has been peer reviewed. 
troponin I was $0.55 \mathrm{ng} / \mathrm{mL}$ (normal $<0.05 \mathrm{ng} / \mathrm{mL}$ ), and creatine kinase $\mathrm{MB}$ was $6 \mathrm{ng} / \mathrm{mL}$ (normal $0-7 \mathrm{ng} / \mathrm{mL}$ ). The chest radiograph was interpreted as normal. A repeat ECG obtained in our ED showed a sinus tachycardia with persistent ST-segment elevation in the precordial leads V1 to V3 with minimal STsegment depression in leads V5 to V6 (Figure 1). An $\mathrm{S}_{1} \mathrm{Q}_{3}$ pattern consistent with right-heart strain was noted.

Despite findings consistent with ST elevation myocardial infarction (STEMI), the patient remained asymptomatic while in the ED, and his ECG did not appear to be evolving. On the recommendation of Cardiology, an echocardiogram was obtained. This demonstrated normal left ventricular function, moderate right ventricular dilation, and right ventricular freewall hypokinesia with preserved apical contractility. The patient was immediately taken to the cardiac catheterization laboratory for urgent reperfusion. The results, however, revealed no culprit lesion in the coronary arteries responsible for the ST-segment changes.

A computed tomographic angiogram (CTA) of the chest was then obtained (Figure 2). This revealed a large saddle thrombus extending from the pulmonary trunk into all branches of the right pulmonary artery, resulting in markedly decreased blood flow to the entire right lung. Pulmonary emboli were also seen in all upper segmental branches of the left pulmonary artery as well as multiple lower segmental branches. The patient was started on a heparin drip and admitted to the intensive care unit, where he remained hemodynamically stable. The following day, lower extremity Doppler ultrasonography revealed extensive thrombus in the left external iliac vein, and the patient underwent placement of an inferior vena cava filter. $\mathrm{He}$ continued to do well and was transferred back to his long-term facility after a 6-day hospitalization.

\section{DISCUSSION}

Pulmonary embolism (PE) is an uncommon but important cause of ST-segment elevation on ECG (Table 1)..$^{2-5}$ This finding is seen in approximately $5 \%$ of submassive and in up to $48 \%$ of massive pulmonary emboli. ${ }^{6} \mathrm{ST}$-segment deviation in the setting of $\mathrm{PE}$ is believed to be due to myocardial strain, that is, the same mechanism responsible for elevation of cardiac troponin in this setting. The most common ECG changes found in a patient with $\mathrm{PE}$ include nonspecific

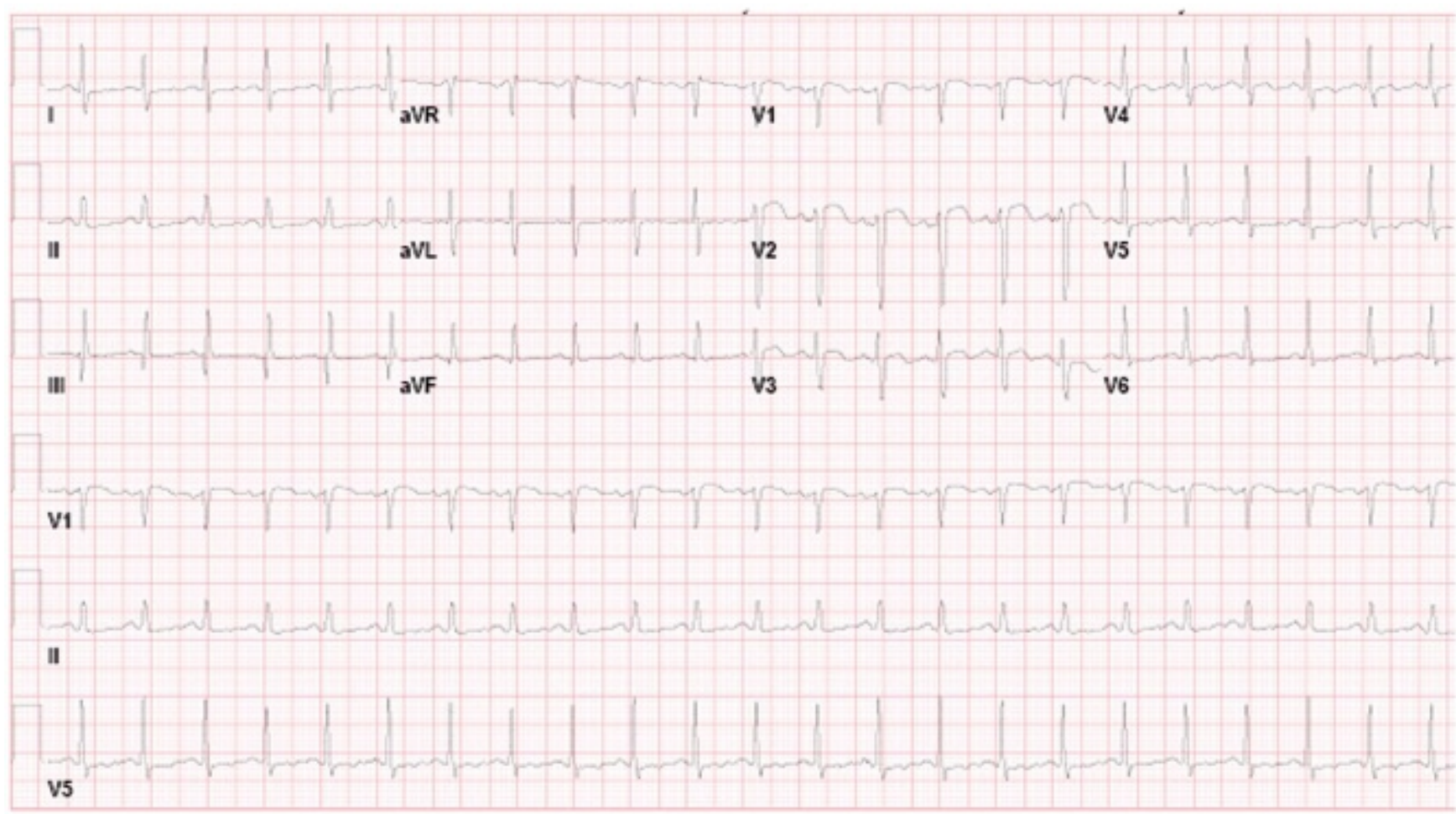

Figure 1. Electrocardiogram demonstrating sinus tachycardia, $\mathrm{ST}$ elevation $\mathrm{V} 1-\mathrm{V} 3, \mathrm{~S}_{1} \mathrm{Q}_{3}$ and nonspecific $\mathrm{ST}$-T wave changes. 


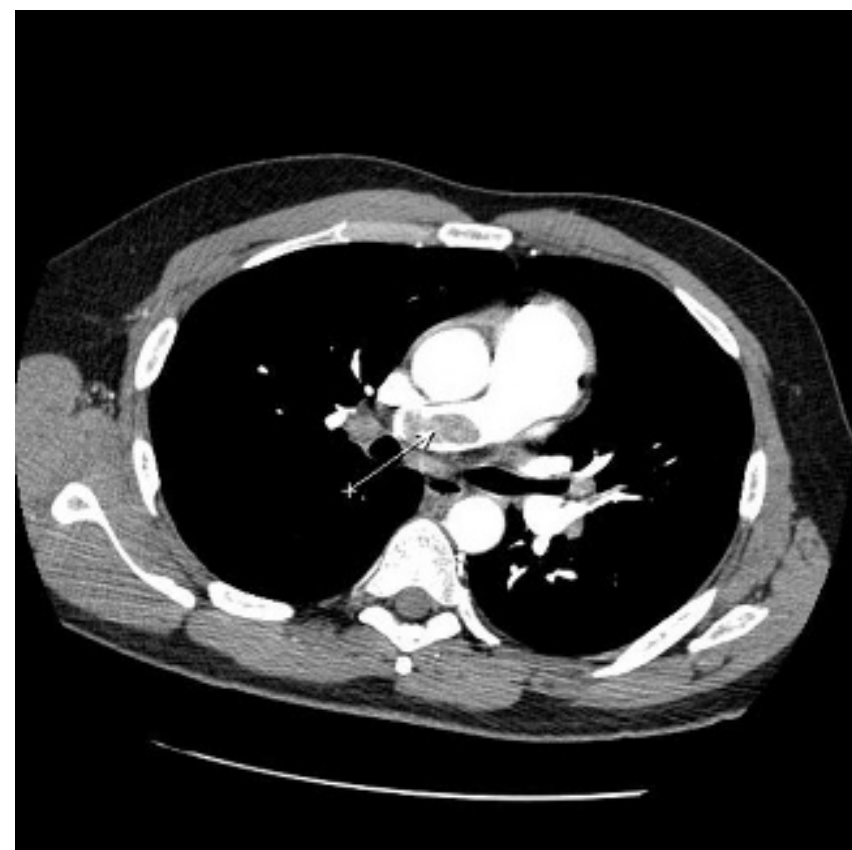

Figure 2. Computed tomographic angiogram of a pulmonary artery thrombus (arrow).

ST-T wave changes (often $\mathrm{T}$ wave flattening or minor inversions), sinus tachycardia, and $\mathrm{S}$ waves $>1.5 \mathrm{~mm}$ in leads $\mathrm{I}$ and $\mathrm{aV}_{\mathrm{L}} \cdot{ }^{7}$ The $\mathrm{S}_{1} \mathrm{Q}_{3} \mathrm{~T}_{3}$ sign (present in $<$ $20 \%$ of cases of $\mathrm{PE}$ ) is seen with cor pulmonale and is a manifestation of pressure and volume overload on the right ventricle. ${ }^{8}$

Obtaining an echocardiogram to confirm the diagnosis of STEMI prior to reperfusion should be considered only when the diagnosis is in doubt,

Table 1. Various conditions reported to cause ST-segment elevation

Acute myocardial infarction

Aortic dissection

Pulmonary embolism

Tension pneumothorax

Perforating ulcer

Boerhaave syndrome

Takotsubo cardiomyopathy

Brugada syndrome

Hyperkalemia

Acute pericarditis

Left ventricular aneurysm

Cardioversion

Prinzmetal angina

Male-pattern ST-segment elevation

Early repolarization

Left ventricular hypertrophy

Left bundle branch block commonly in the setting where aortic dissection or left ventricular aneurysm is a consideration or in the setting where an ECG pattern interrupts proper interpretation of the ST segments. ${ }^{9}$ In our case, the echocardiogram was ordered based on the patient's absence of symptoms and lack of ECG progression when compared to the initial ECG obtained in the skilled nursing facility. Interestingly, the finding described by the echocardiogram (ie, normal wall motion at the apex and abnormal wall motion of the mid-right ventricular free wall) has been associated with acute PE and is termed McConnell sign. In a prospective study of 85 hospitalized patients with right ventricular dysfunction, McConnell sign had a sensitivity of $77 \%$ and a specificity of $94 \%$ for the diagnosis of acute PE. ${ }^{10}$ A subsequent study found a similar sensitivity, but the specificity of this sign for $\mathrm{PE}$ plummeted to $33 \%$ when patients with right ventricular infarction were also examined. ${ }^{11}$

Imaging via echocardiography and/or CTA of the chest may be useful in patients who have ST-segment elevation and who do not have a readily identifiable lesion on coronary angiography. The potential exists for bedside echocardiography to pick up right ventricular strain, allowing clinicians the chance to include massive (previously unconsidered) $\mathrm{PE}$ in their differential diagnosis.

In summary, the ECG and echocardiogram findings in PE can overlap with STEMI. Given that the timing of reperfusion is paramount in STEMI, patients who present with ST-segment elevation should undergo rapid evaluation for coronary reperfusion therapy. Obtaining an echocardiogram to confirm the diagnosis of STEMI prior to reperfusion should be considered only when the diagnosis is in doubt, commonly in the setting where aortic dissection or left ventricular aneurysm is a consideration or in the setting where an ECG pattern interrupts proper interpretation of the ST segments. Following unremarkable coronary angiography, a CTA of the chest should be obtained to exclude other life-threatening causes of ST-segment elevation.

Competing interests: None declared.

\section{REFERENCES}

1. Fishman I, Benedict R, Bakshi R, et al. Construct validity and frequency of euphoria sclerotica in multiple sclerosis. $\mathcal{F}$ Neuropsychiatry Clin Neurosci 2004;16:350-6. 
2. Kurisu S, Sato H, Kawagoe T. Tako-tsubo-like left ventricular dysfunction with ST-segment elevation: a novel cardiac syndrome mimicking acute myocardial infarction. Am Heart 7 2002;143:448-55.

3. Monterrubio Villar J, Fernández Bergés D, Alzugaray Fraga R, et al. ST elevation and tension pneumothorax. Rev Esp Cardiol 2000;53:467-70.

4. Mosseri M, Eliakim R, Mogle P. Perforation of the esophagus mimicking myocardial infarction. Isr $7 \mathrm{Med} S c i$ 1986;22:451-4.

5. Wang K, Asinger R, Marriott H. ST-segment elevation in conditions other than acute myocardial infarction. $N$ Engl 7 Med 2003;349:2128-35.

6. Mittal SR, Maheshwari M. Electrocardiographic changes in submassive pulmonary embolism. Indian Heart 7 2005;57:80-3.

7. Rodher M, Makropoulos D, Turek M, et al. Diagnostic value of the electrocardiogram in suspected pulmonary embolism. Am 7 Cardiol 2000;86:807-9.
8. Panos R, Barish R, Whye D, et al. The electrocardiographic manifestations of acute pulmonary embolism. 7 Emerg Med 1988;6:301-7.

9. Antman EM, Anbe DT, Armstrong PW, et al. $A C C / A H A$ guidelines for the management of patients with ST-elevation myocardial infarction: a report of the American College of Cardiology/American Heart Association Task Force on Practice Guidelines (Committee to Revise the 1999 Guidelines for the Management of Patients With Acute Myocardial Infarction). 2004. Available at: www.acc.org/clinical/guidelines/stemi/ index.pdf (accessed June 2010).

10. McConnell MV, Solomon SD, Rayan ME, et al. Regional right ventricular dysfunction detected by echocardiography in acute pulmonary embolism. Am 7 Cardiol 1996;78:46973.

11. Casazza F, Bongarzoni A, Capozi A, et al. Regional right ventricular dysfunction in acute pulmonary embolism and right ventricular infarction. Eur 7 Echocardiogr 2005;6:11-4. 